\title{
特集 「最近の脳科学」
}

\section{事象関連電位からみた小児の認知発達}

\author{
㴊上達夫 \\ 日本大学医学部小坚科学系小児科学分野
}

\section{Event-Related Potentials in Children: Evaluation of Cognitive Development}

Tatsuo FUCHIGAMI

Pediatrics and Child Health, Nihon University School of Medicine

\begin{abstract}
Event-related potentials reflect various cognitive functions and include the mismatch negativity and P300. The mismatch negativity is said to reflect the process in which stimuli are detected automatically. The mismatch negativity requires no concentration of attention or understanding of the subject, and is useful for objectively evaluating the cognitive ability in newborns. The P300 wave is generally interpreted as a neural correlate of decision-making or of signal detection by an actively attentive subject. Studies of event related potentials in children, based on a task relevant oddball paradigm, reveal a decrease in the latency of P300 with increasing age. This developmental change could be related to maturation phenomena in cognitive processes. Squires et al. delineated P3a and P3b components in P300. In our study, P300 in a state of ignoring, likely corresponds to P3a (passive attention), whereas conventional P300 corresponds to P3b (active attention). These findings indicate a developmental difference between the P3a and P3b potentials. The development of fundamental cognitive function like passive attention reaches the adult level at an earlier age than the cognitivelike active attention. To evaluate auditory spatial cognitive function, age correlations for event-related potentials in response to auditory stimuli with a Doppler effect were studied in normal children. From the age of 4 years, the P300 latency for the enlarged tone with a Doppler effect shortened more rapidly with age than did the P300 latency for tonepips, and the latencies for the different conditions became similar towards the late teens. These findings provide evidence that auditory cognitive function, including auditory spatial cognitive function, had reached the adult level by about this age. P300 in response to different stimuli may provide more detailed information that could enable the evaluation of cognitive function development in children.
\end{abstract}

Key words: event related potentials, mismatch negativity, P300, cognitive function, children 事象関連電位，ミスマッチ陰性電位，P300，認知機能，小児

(J. Nihon Univ. Med. Ass., 2011; 70 (3): 174-178)

\section{はじめに}

中枢神経は, 他の藏器に比較して乳幼児期に著しく成 長するのが特徵である.ヒトは脳が未熟な状態で生ま れ，1 歳前後までに倍増し成人脳重量との比率は $60 \%$, 3 歳で70\%，6 歳で90\%に達する。

聴覚の発達に関してみると, 胎児期においてヒトで は, 胎児にも音刺激に対応反応として, 胎動や心拍数の 変化などが知られている ${ }^{1,2)}$. 新生児・乳児期早期には， ある程度大きな音刺激に対して，Moro 反射樣の動作， 瞬目反射などの聴覚反射か認められる. 兴の後, 大脳皮 質の発達に伴ってこれらの聴覚反射は次第に抑制され， より高次元の行動反応に置き換えられる．また，音の感 度も発達し, より小さな音に対する反応がみられるよう になり, さらに言語としての音の理解, 使用の初期の発 達が認められる. 幼児期には, 音の感度, 方向性, 弁 別, 認知などの面で著しい発達か認められ, なかでも言 語理解の面で飛躍的発達をとげる.聴覚は単に聴力を意 味するのではなく, 音に気づき, 音の強さ, 種類, 音 色, 音の高さ, リズムなどを区別し, 認知するといった さまざまな内容を含んだ複雑な機能である．このように
聴覚認知一つをとっても，小児期の精神神経機能の発達 変化は, 著しい. 本稿では, 高次認知機能の客観的評価 法として注目されている大脳誘発電位の一つである事象 関連電位について概説し，事象関連電位からみた小児の 聴覚認知機能の発達について述べる .

\section{I. 事象関連電位}

ヒトにある感覚刺激を呈示し，脳波を記録すると，刺 激呈示と一定の時間関係をもつ電位変動が脳波上に得ら れる.大脳誘発電位 (evoked potentials) は，外的刺激依 存性の外因性電位と外的刺激と関連しながらも相対的に 独立した内因性電位に区別される.大脳誘発電位のうち 長潜時の成分は, 刺激に対する注意や刺激の持つ意味に よって変動することより外的事象に関連した内因性成分 を含むものと考えられ，事象関連電位 (event related potentials) と呼ばれている. 認知はヒトの知的活動におけ る知覚, 注意, 学習, 記憶, 意志決定, さらに感情など にかかわる一連の情報処理過程とみなされる．事象関連 電位は, ミスマッチ陰性電位 (mismatch negativity: MMN または N2a)，N200，P300， slow wave のほか，随伴陰性 変動 (contingent nagative variation: CNV), N400, 運動関 
連電位 (movement-related cortical potentials: MRCPs) な どが含まれる.

本稿では事象関連電位の代表成分であるミスマッチ陰 性電位, P300 からみた小児の認知機能の発達について述 ベる .

\section{1) ミスマッチ陰性電位}

聴覚刺激を用いた課題において，標準刺激の中にまれ に偏倚刺激 (周波数, 強度, 持続時間, 空間的部位, 音 素などの物理的特徵の偏倚) が出現すると，偏倚刺激に 対して刺激後約 $200 \mathrm{msec}$ に頂点をもつ前頭部優位の陰 性電位が, 注意側, 非注意側および標的, 非標的を問わ ず出現し，これをミスマッチ陰性電位 (Mismatch negativity: 以後 MMN と略す) ${ }^{3)}$ あるいは N2a と呼ぶ . 刺激 の偏倚の程度が大きいと, MMN の振幅増大 , 潜時と持 続時間の短縮が起こる. 分布は感覚樣式に特異性を示 し, 課題効果や主観的要因とは関連しないことから，短 期記憶に関連する自動的，かつ前認知的な感覚過程を反 映する一種の定位反応と考えられている4).

2) $P 300$

事象関連電位のうち後期陽性波形は, P3 または P300 と呼ばれている5)．P300 は被験者に特定の感覚刺激 (聴 覚, 視覚, 体性感覚刺激など) を与え, 关れを認知, 識 別させ，一定の課題を実行させる場合に，刺激後約 300 $\operatorname{msec}($ 課題か灘しいと延長する)の潜時で出現する陽性成 分をいう (Fig. 1) . P300 は，感覚刺激に対する脳内での 情報処理過程に関連して惹起され, 頂点潜時は刺激評価 時間を反映するとされており，振幅は標的刺激に対する 選択的注意や配分される処理資源量を反映するとされて (る6 8). Squires ら ${ }^{9)}$ は，P300 成分を早期成分である $\mathrm{P} 3 \mathrm{a}$ と後期成分である P3b の 2 種類に分類し, P3b が課 題要請に応じて標的刺激を検出したときに出現するのに 対し, P3a 成分は課題遂行とは無関係に出現する波であ り，外的刺激によって受動的に惹起される生来備わって いる注意機構, すなわち定位反射に関わる電位とされて いる . 注意 (attention) を能動的注意 (active attention) と 受動的注意 (passive attention) に分けると, P3a 成分は受 動的注意に P $3 b$ は能動的注意に関連する波形といえる.

\section{II. 事象関連電位からみた聴覚認知機能}

1) 受動的注意と能動的注意

事象関連電位を用いた小児での検討は，主に能動的注 意に関する P300 (P3b) に関するものが多い10〜16).この $\mathrm{P} 3 \mathrm{~b}$ 成分の測定には, 呈示された刺激から，できるだけ 速く注目すべき標的刺激を弁別し，キーを押すまたは数 を数えるといった能力を必要とする．このためこの高度 な課題遂行が可能となる正常小児の年齢は, 4 歳以上と 考えられている10).この年齢以下では, 課題遂行が困難 であり P3b 測定はまず不可能である .この年齢以下の小 児においては, 通常, 呈示刺激に特別な課題を必要とし

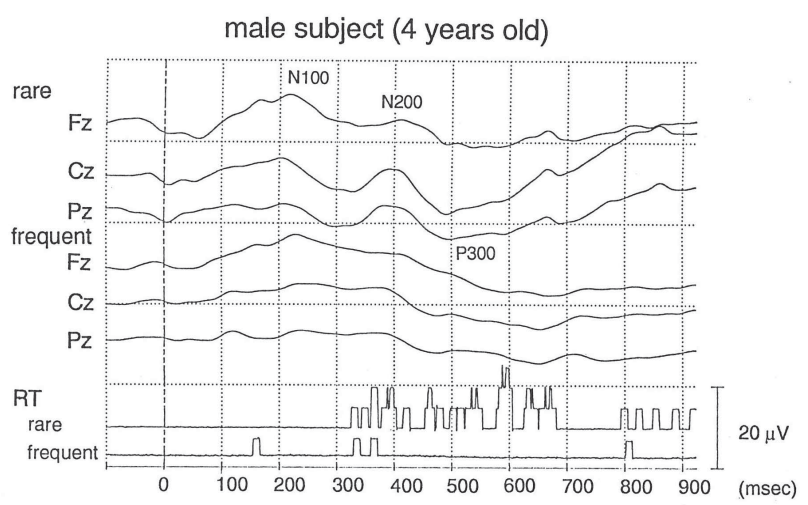

female subject ( 13 years old)

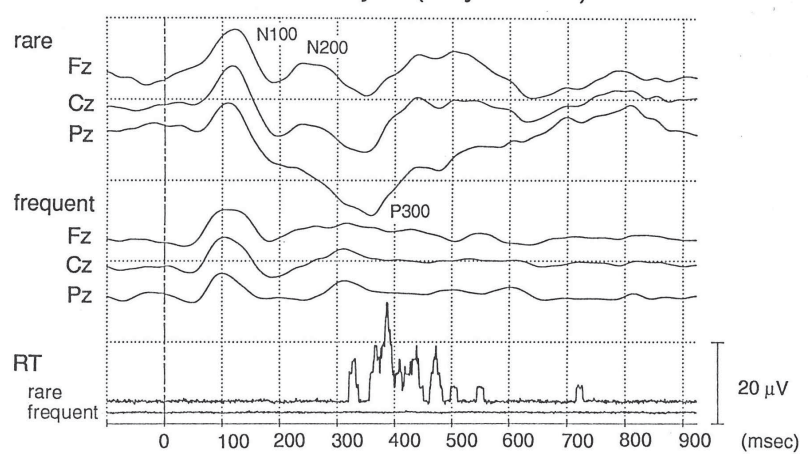

Fig. 1 Event-related potentials and reaction time (RT) of a 4-yearold male and 13-year-old female in the attending condition.

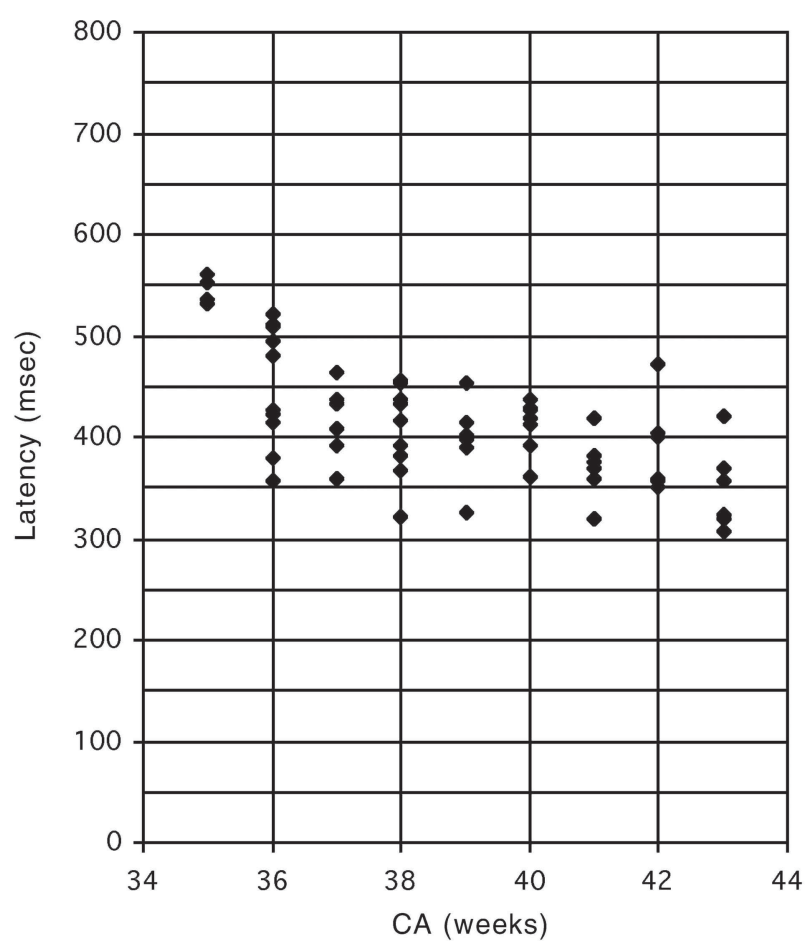

Fig. 2 Changes in auditory mismatch negativity latency in normal newborns with conceptional age. The latency becomes shorter with conceptional age and is markedly shortened between 36 and 37 weeks. CA indicates conceptional age. 
ない MMN や P3a 成分を用いて検討が行われる .

我々は, 新生児期の認知機能の解明のために在胎 35 か ら 43 週の正常 72 例の新生児を対象に聴覚および視覚刺 激を用いた MMN の検討を行った17)．光の結果 MMN 波 形は，35 週の児で記録可能であった .この MMN は， 在胎週数の増加とともに潜時の短縮がみられた (Fig. 2) . このことは，この時期にすでに短期記憶に関連する自動 的, かつ前認知的な感覚過程は確立されており，在胎週 数の増加とともに発達していくと推測された . また 1 歳 以上の正常小児での純音を用いた $\mathrm{P} 3 \mathrm{a}$ と $\mathrm{P} 3 \mathrm{~b}$ 成分の発達 的変化の検討18) では, 关れ光れ異なる発達変化がみられ た (Fig. 3). 受動的注意に関係する P 3a 成分の発達的変 化は，約 12 歳で成人レベルに達していた . また能動的注 意に関する P $3 b$ 成分は約 16 歳で成人レベルに達すると いった異なる発達的変化か認められた .このことは聴覚 認知機能において，より基本的機能である受動的認知機 能が能動的認知機能より若年で完成すると推測される.

4 歳以上での単一な純音の聴覚刺激での小児のP300 の 研究は, 年齢の増加に伴い P300 (P3b) 潜時の短縮がみら れる10〜16). これは小児の認知機能が , 年齢の増加にと もない発達することを意味している．

2) 聴覚空間認知

生体が空間，広がりを認知することを空間認知 (spatial perception) といい，空間知覚 (space perception), 空間覚 (space sense) とも呼ばれる.空間認知は, 視覚, 聴覚, 触覚などが共働して行われ, 位置, 方向, 大小, 形状, 距離などを識別する . 音の空間認知は聴覚系の重要な機 能で, 音源の位置は左右光れ光れの耳に到達する時間 差, 音の強さ, 音波の位相差を識別することにより行わ れる19〜22) . 情報を感知する細胞は上オリーブ核, さら に上位の聴覚中枢に存在する23 26) . 最近の神経画像的 研究において, 人間の聴覚空間認知機能は前頭前野や後 頭頂野の関与を示している27,28).

日常遭遇する音源は, 通常固定したものより移動して いるものがほとんどである . 小児において移動している 音源に関する研究はほとんど報告がなく29,30), 移動音の 反応に関連する脳機能は，いまだ十分解明されていな い. 加我 ${ }^{30)}$ は, 音源の位置に関する認知発達について検 討し，4歳になれば大人とほぼ同等な音源の位置判断が 可能になると報告している．筆者ら ${ }^{31)}$ は，ドップラー効 果を付け近づいてくるように聞こえる三次元増大音 (Fig. 4) ${ }^{29)}$ を用いて事象関連電位 P300 (P3b) を測定し，小児 の聴覚空間認知機能の発達的評価をおこなった . 筆者ら の三次元の聴覚刺激を用いた事象関連電位の検討でも $\mathrm{P} 300$ は, 単一純音刺激と同樣に 4 歳以上の小児で測定 可能であった .

作業記憶 (working memory) は, Baddeley ら ${ }^{32)}$ が短期 記憶の拡張概念として提唱した処理メカニズムである . 作業記憶は, 理解, 学習, 推論といった広い範囲の認知

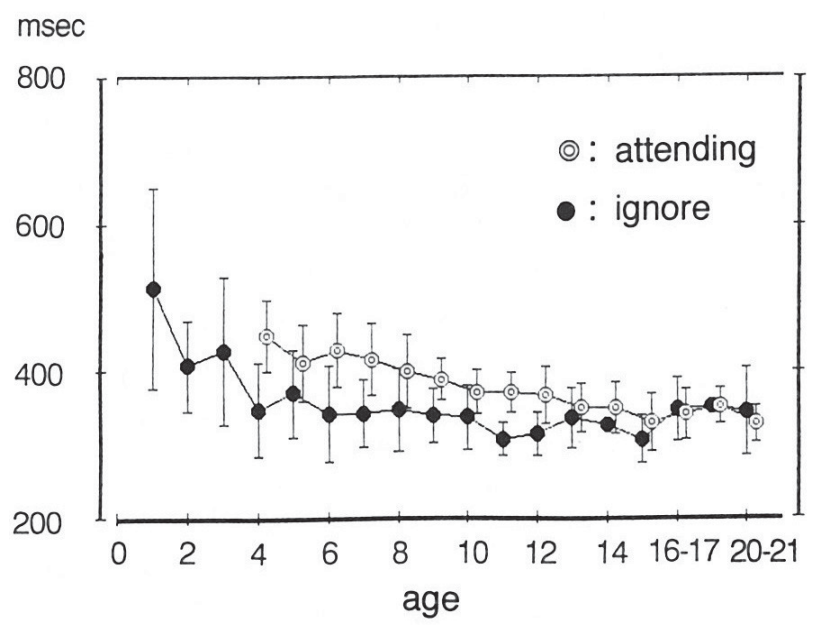

Fig. 3 Age-related P300 latency differences between ignore and attending conditions.

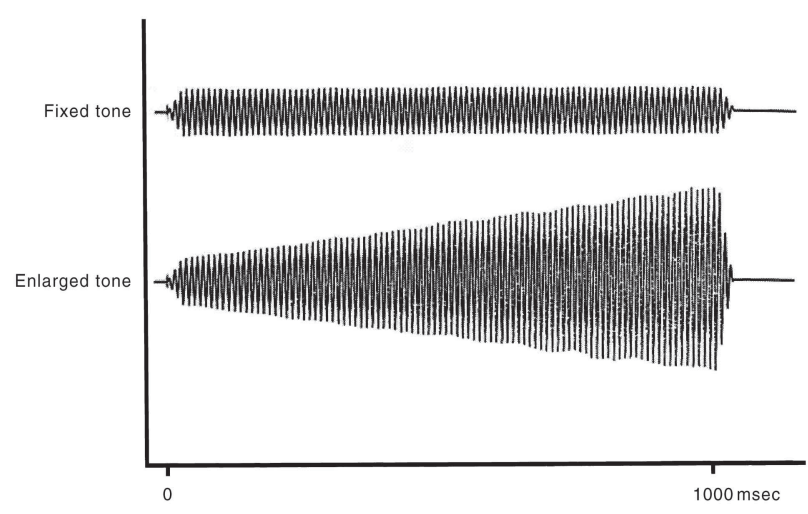

Fig. 4 Stimuli of the event-related potentials. Event related potentials were elicited by two types of tone; fixed tones and enlarged tones with Doppler effect.

的課題の遂行中の情報の操作と一時的貯蔵のためのシス テムに関与しており, 短期記憶の活動的な維持の樣相を 示しているともいえる．P300の脳内起源については，い まだ議論の余地があるが, ヒトの脳深部電極記録や磁気 領域の研究では, 少なくとも P300 成分の一部は, 学習 や記憶に関係する海馬を含む中側頭葉が起源と考えられ ている ${ }^{33,34)}$. これは ,「作業記憶の維持に必要な働き」の 指標としての P300 の理論的解釈 ${ }^{35)}$ を支持するものであ る.

Ladish と Polich ${ }^{36)}$ は, 小児の短期記憶は, 年齢ととも に増加し，P300 潜時の短縮に関連性があり，P300 が認 知発達の指標となると述べている.

Vuontela ら ${ }^{37)}$ は, 6〜13 歳の学童における聴覚および 視覚空間認知の作業記憶の年齡および性の影響を検討し た．炎の結果，聴覚および視覚空間認知の作業記憶機能 は, 年齢か増加するにつれ改善した . また，視覚の作業 記憶機能は, 11〜13 歳ではすでに成人レベルに到達して いたが，聴覚空間認知の作業記憶機能は，11〜13 歳で は，まだ成人レベルに達していなかったと述べている . 


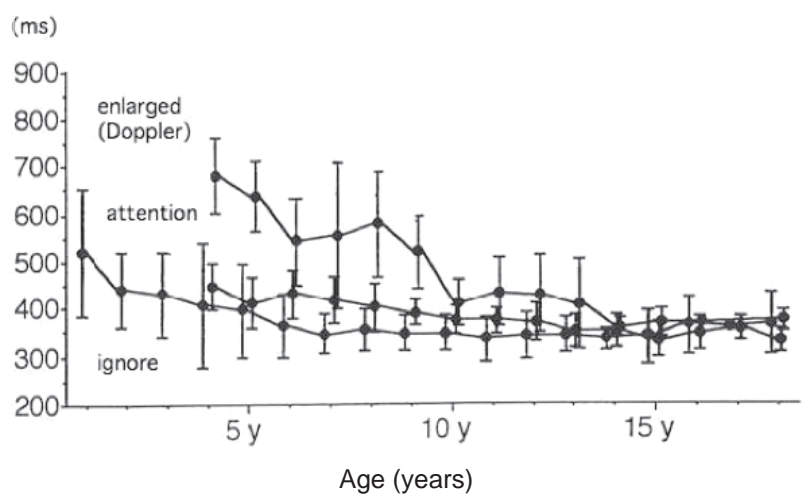

Fig. 5 Comparison of changes in P300 latencies in response to different auditory stimuli. enlarged (Doppler) indicates 3D auditory stimuli in attending condition, attention indicates tone stimuli in attending condition (P3b), ignore indicates tone stimuli in ignore condition (P3a).

このことは, 11〜13 歳では, 聴覚空間認知を含む聴覚認 知機能は，まだ成人レベルに達せず，未完成の状態であ ることを示している.我々の三次元の聴覚刺激を用いた P300の検討でも聴覚空間認知機能は ,11〜 13 歳では未完 成であり 15 歳以降に成人レベルに達すると考えられる .

筆者らの研究では, 刺激を無視した受動的課題で測 定した P300 (P3a) は，1 歳で測定可能であったが, 能動 的課題における P300 (P3b) は, 3 歳以下ではわれわれ の指示が理解できず測定不可能であった . 筆者らの検 討 $10,18,31)$ や加我の報告 ${ }^{30)}$ から総合的に判断すると 4 歳 で移動音を含む聴覚刺激の弁別・判断が可能となる聴覚 空間認知機能の基本的機能ができあがると推測できる . 純音を含む能動的課題での P300 は 4 歳からおよ年 15 歳 までは, 年齢の増加とともに徐々に潜時の短縮がみられ た . 三次元音を用いた P300 潜時は，純音でのP300 よ り急激な潜時の短縮が観察された . しかし 15 歳以降は 3 種類の異なる音刺激を用いても P300 潜時はほぼ同程 度であつた ${ }^{31)}$ (Fig. 5) . これらの結果から移動音をイメー ジした三次元音は, 年少児において単純な純音より判別 し認識するのが困難と考えられたが, 15 歳以降になると P300 潜時は刺激音の種類の違いによる判別レベルに差は 認められなくなり，成人レベルに達していた .これらの ことは, 聴覚空間認知を含む聴覚認知機能は, 15 歳以降 に成人レベルに達し完成すると考えられる .

\section{おわりに}

事象関連電位の測定は, 小児においても高次認知機能 の客観的評価法として有用である . 本稿で述べたように 異なる刺激を用いて MMN , P300 などの成分を測定する ことより，小児の認知機能におけるより詳細な検討が可 能となりうる .

\section{文献}

1) Murphy KP, Smith CN. Response of foetus to auditory stimulation. Lancet 1962; 7236: 972-973.

2) Johansson B, Wedenberg E, Westin B. Measurement of tone response by human foetus. Acta Otolaryngol 1964; 57: 188 192.

3) Näätänen, R. Processing negativity: an evoked-potential reflection of selective attention. Psychol Bull 1982; 92: 605-640.

4) Näätänen, R. The mismatch negativity. In: Näätänen, R editor. Attention and brain function. New Jersey: Laurence Erbaum Associates, 1992: 136-200.

5) Sutton S, Braren M, Zubin J, et al. Evoked potential correlates of stimulus uncertainty. Science 1965; 150: 1187-1188.

6) Smith DBD, Donchin E, Cohn L, et al. Auditory average evoked potentials in man during selective binaural listening. Electroenceph Clin Neurophysiol 1970; 19: 470-475.

7) Hillyard SA, Squires KC, Bauer JW, et al. Evoked potential correlates of auditory signal detection. Science 1971; 172: $1357-$ 1360.

8) Paul DD, Sutton S. Evoked potential correlates of response criterion in auditory signal detection. Science 1972; 177: 362-364.

9) Squires NK, Squires KC, Hillyard SA. Two varieties of long latency positive waves evoked by unpredictable auditory stimuli in man. Electroenceph Clin Neurophysiol 1975; 38: 387-401.

10) Fuchigami T, Okubo O, Fujita Y, et al. Auditory event-related potentials and reaction time in children: Evaluation of cognitive development. Dev Med Neurol 1993; 35: 230-237.

11) Goodin DS, Squires KC, Henderson BH, et al. Age-related variations in evoked potentials to auditory stimuli in normal human subjects. Electroenceph Clin Neurophysiol 1978; 44: $447-458$

12) Courchesne E. Neurophysiological correlates of cognitive development: Changes in long-latency event-related potentials from childhood to adulthood. Electroenceph Clin Neurophysiol 1978; 45: 468-482.

13) Polich J, Howard L, Starr A. Effects of age on the P300 component of the event-related potentials from auditory stimuli: Peak definition, variation and measurement. J Gerontol 1985; 40: 721-726.

14) Finley WW, Faux SF, Hutcheson J, et al. Long-latency eventrelated potentials in evaluation of cognitive function in children. Neurology 1985; 35: 323-327.

15) Martin L, Barajas JJ, Fernandez R, et al. Auditory event-related potentials in well-characterized groups of children. Electroenceph Clin Neurophysiol 1988; 71: 375-381.

16) Pearce JW, Crowell DH, Tokioka A, et al. Childhood developmental changes in the auditory P300. J Child Neurol 1989; 4: 100-106.

17) Tanaka M, Okubo O, Fuchigami T, et al. A study of mismatch negativity in newborns. Pediatr Int 2001; 43: 281-286.

18) Fuchigami T, Okubo O, Ejiri K, et al. Developmental changes in P300 wave elicited during two different experimental conditions. Pediatr Neurol 1995; 13: 25-28.

19) Strybel T, Manligas CL, Perrott DR. Auditory apparent motion under binaural and monaural listening conditions. Percept Psychophys 1989; 45: 371-377.

20) Middlebrooks JC, Green DM. Sound localization by human listeners. Ann Rev Psychol 1991; 42: 135-159.

21) Phillips DP, Brugge JF. Progress in neurophysiology of sound localization. Ann Rev Psychol 1985; 36: 245-274.

22) Phillips DP. Representation of acoustic events in the primary 
auditory cortex. J Exp Psychol Hum Percept Perform 1993; 19: 203-216.

23) Mondor TA, Zatorre RJ. Shifting and focusing auditory spatial attention. J Exp Psychol Hum Percept Perform 1995; 21: 387 409.

24) Wu SH, Kelly JB. Binaural interaction in the lateral superior olive: Time difference sensitivity studied in mouse brain slice. J Neurophysiol 1992; 68: 1151-1159.

25) Goldberg JM, Brown PB. Functional organization of the dog superior olivary complex: an anatomical and electrophysiological study. J Neurophysiol 1968; 31: 639-656.

26) Heffner HE, Heffner RS. Effect of bilateral auditory cortex lesions on sound localization in Japanese macaques. J Neurophysiol 1990; 64: 915-931.

27) Bushara KO, Weeks RA, Ishii K, et al. Modality-specific frontal and parietal areas for auditory and visual spatial localization in humans. Nature Neurosci 1990; 2: 759-766.

28) Weeks RA, Aziz-Sultan A, Bushara KO, et al. A PET study of human auditory spatial processing. Neurosci Lett 1990; 262: $155-158$.

29) Yamamori H, Okubo O, Harada K. Brain evoked potentials of 3-D auditory stimuli. Pediatr Int 2002; 44: 420-426.

30) Kaga M. Development of sound localization. Acta Paediatr Jpn
1992; 34: 134-138.

31) Fuchigami T, Okubo O, Fujita Y, et al. Event-related potentials in response to 3-D auditory stimuli. Brain Dev 2009; 31: $577-$ 581.

32) Baddeley AD, Hitch GJ. Working Memory. In: Bower GA, editor. Recent advances in learning and motivation (vol. 8). New York: Academic Press, 1974; 47-90.

33) Halgren E, Squires N, Wilson C, et al. Endogenous potentials in the human hippocampal formation and amygdala by infrequent events. Science 1980; 210: 803-805.

34) Okada YC, Kaufman L, Williamson SJ. The hippocampal formation as a source of the slow endogenous potentials. Electroencephalogr Clin Neurophysiol 1983; 55: 417-426.

35) Donchin E, Karis D, Bashore TR, et al. Cognitive psychophysiology and human information processing. In: Coles MGH, Donchin E, Porges SW, editors. Psychophysiology: Systems, processes, and applications. New York: Guilford Press, 1986; 244-267.

36) Ladish C, Poloch J. P300 and probability in children. J Exp Child Psychol 1989; 48: 212-223.

37) Vuontela V, Steenari MR, Carlson S, et al. Auditoryspatial and visuospatial working memory in 6-13 year old school children. Learn Mem 2003; 10: 74-81. 